\title{
Neurosurgical electives: Operating room survival guide
}

\section{Shahzad Shamim}

Aga Khan University, shahzad.shamim@aku.edu

Zain A. Sobani

Aga Khan University

Follow this and additional works at: https://ecommons.aku.edu/pakistan_fhs_mc_surg_neurosurg

Part of the Neurology Commons, Neurosurgery Commons, and the Surgery Commons

\section{Recommended Citation}

Shamim, M. S., Sobani, Z. A. (2012). Neurosurgical electives: Operating room survival guide. World Neurosurgery, 78(1-2), 18-19.

Available at: https://ecommons.aku.edu/pakistan_fhs_mc_surg_neurosurg/136 


\section{Neurosurgical Electives: Operating Room Survival Guide}

\section{Shahzad Shamim and Zain A. Sobani}

A major event in the final academic year of most medical schools, from a student's perspective, is his or her clinical electives. Although many senior physicians and faculty members believe that the programs are of uncertain academic value and have proposed cutting down on the clinical electives and investing the time regained in structured academic activities $(6,7)$ a recent survey revealed that the most common reason ( $90 \%$ ) for medical schools to incorporate visiting elective programs was "recruitment for residency programs" (4). In a reciprocating factor students ranked "desire to do a residency at the institution" as the primary reason for doing an elective at a certain institution (4).

Because most students already have some direction regarding their future career plans by this time (2), the elective process is converted into a cutthroat match in which students are willing to use every trick in the book to impress residency program directors, especially in competitive fields such as neurosurgery. When these students arrive on the neurosurgery floor, the busy nature of the service does not allow structured or organized teaching (I); thus, they are subjected to more self-directed learning than ever before. The stress to impress their peers combined with the pressures to maintain professional discipline is enormous, in addition to the potential to do more harm than good, is obvious. It is also the responsibility of neurosurgery team members to allow certain degree of freedom to these young aspirants, without obstructing clinical activities or threatening patient care. The neurosurgery operating room (OR) is a work of art, where precision is the medium $(3,5)$. This prerequisite precision in the neurosurgery OR offers a greater challenge in maintaining this balance than any other field.

The first thing to know is that although the archetypical know-itall surgeons of yesteryear are now almost extinct, with most of them having evolved into the more modern, affable surgeons, willing to listen to, and consider others' opinion, neurosurgeons in general have not. This species of surgeons unfortunately refuse to evolve, and a typical neurosurgeon can be termed as the last of the surviving autocrats on Earth. He is a tyrant, a dictator, a vicious ruler in a kingdom without a whisper of democracy. He looks into the mirror every day and sees Harvey Cushing. His only goal is the successful completion of his surgery and for him to return home in his flashy new car in time for dinner and the late night movie. Anything coming in between him and his goal is doomed for disaster.

His OR is his fort, and the most important thing that you need to remind yourself is that you cannot enter his fort without his permission. Period. Don't even consider touching the door, let alone open it. If it was up to him, the neurosurgery OR would be on the highest room of the tallest tower of the fort, with a fire breathing dragon guarding it. However important you may consider your presence in the OR to be, for the neurosurgeon, you are just a piece of furniture, obscuring his light, using his oxygen, and adding to the clutter. Unfortunately, if you want to become a neurosurgeon, the only way to do so is to bear with this monster. If you still want to enter the neurosurgery OR, read on. Otherwise, be content with your life as the "other" surgeon.

- Before coming to the OR, read about the case. You must know the patient's history and neurological examination, but equally important is the knowledge of relevant anatomy. The involved residents will be your best resource for this. In fact, go on to discuss the possible operative plan.

v Give extra time to the images before the start of surgery trying to identify as many anatomical structures as you can. That's probably what will be thrown at you. Study on a model if you have time. During surgery the head is fixed at variable positions and knowledge of anatomy is tested at its fullest. Anatomical models and neurosurgical atlases help in making mental three-dimensional relationships.

- Be prepared for long hours. One of the best pieces of advice that a neurosurgery resident gave me during my elective was "neurosurgeons eat prophylactically." Always grab a light snack before entering the OR; you never know how long the procedure will last and when you will get a chance to eat. If you want to go home early or have a proper lunch/dinner break, go find another OR.

\section{Key words \\ - Electives \\ - Medical students \\ - Neurosurgical OR}

\section{Abbreviations and Acronyms}

OR: Operating room

Section of Neurosurgery, Department of Surgery, Aga Khan University, Karachi, Pakistan

To whom correspondence should be addressed: Zain A. Sobani [E-mail: zsobani@gmail.com]
Disclaimer: This article is written with both humorous as well as academic contexts in mind. Readers are therefore requested to note that certain portions of the article are exaggerated to create humor. The authors in no way mean to vent their frustrations and would like to add that some of the best times they have experienced have been during their neurosurgical rotations.

Citation: World Neurosurg. (2012) 78, 1/2:18-19.

DOl: 10.1016/j.wneu.2011.04.003

Journal homepage: www.WORLDNEUROSURGERY.org

Available online: www.sciencedirect.com

1878-8750/\$ - see front matter (C) 2012 Elsevier Inc. All rights reserved. 
- A ringing cell phone is akin to professional suicide. It will automate an exclamation or even an expletive, or if you're lucky, at least a frown, so keep your phones on silent or better still, switched off.

- Neurosurgery ORs are typically cooler than other ORs, temperaturewise as well, so you may want to wear a t-shirt underneath your scrubs.

- As you enter the neurosurgery ORs you will realize that they are more crowded than other ORs because of the presence of a larger team and various machines and monitors within the same sized rooms. Given the complexity of the specialty, there are numerous sophisticated (read expensive) machines surrounding the operating table. These may include the neuronavigation system, fluoroscopy units, operating microscopes, drill sets, and so on. Similarly, the anesthesia side is also full of strange gadgets that you do not see in regular operating rooms. Not surprisingly, people have compared the neurosurgery OR of the future to the cockpit of a modern space shuttle (5). When in the OR be careful not to touch anything. Yes, anything.

- Fluoroscopy will often be used in spine cases. Standard precautions of either periodically leaving the OR or wearing a lead apron are to be followed if you want to avoid tumors and also wish to procreate later in life.

- Because most neurosurgical procedures are performed under a microscope, most teaching hospitals have installed video monitors in the OR for observing surgeries so you don't have to be scrubbed to see a case. However, the view under the microscope is far superior and do try to watch at least part of a case from the microscope. For this, you are better off being scrubbed, an opportunity very few of you are likely to get.

- When you do get the opportunity to, scrub till your shoulders hurt, preferably having someone to watch over you. The scrubbing technique is the same although most neurosurgeons prefer double gloving. Be sure to have a plastic apron underneath your gown and covers on your shoes before you scrub, as cranial procedures tend to bleed a lot and standing very close to the drapes with profuse irrigation going on, you may end up with soaking underwear and socksstandard occupational hazard in a neurosurgery OR. Also, bone dust travels in air, so if you don't wear spectacles, you should wear goggles in OR to protect your eyes.
- When scrubbed in, as much as you may be tempted to, do not touch anything, especially the brain. This is not general surgery where you are encouraged to feel everything with the tip of your finger. Neurosurgeons seldom rely on their direct proprioceptive capabilities and use instruments instead, as extensions of their appendages.

- When scrubbed, keep your hands in front and above your waist level at all times and do not put your weight on the patient. Asepsis is more important in neurosurgery OR that any other place on earth, so do not be shy to notify a breach in asepsis to the nurse, even if you only "think" it occurred. Nobody will mind it.

- Like in all ORs, you will be expected to maintain pin-drop silence to allow communication between the operating team. It is advisable to not participate in discussion unless you are invited. Your idea may seem brilliant to you, but there is a good chance it isn't. I don't mean to scare you into being a mute nonparticipating member of the team; your time to speak up will come. The faculty encourages you to ask questions; however, please do when the air is relaxed. How do you know when the air is NOT relaxed? Trust me, you will know!

- If you get to assist, do not preempt surgical steps; do only what you are asked to and gently. If you do not understand or feel that you are not up to any tasks, do not hesitate to ask someone for help. Neurosurgery is done in subcentimeter corridors between vital structures and any disturbance or unexpected movements can be dangerous.

- Although it is against etiquette to leave any OR while a patient is under, if you really have to leave, do not announce it. If you are not scrubbed, whisper to one of the residents for permission and leave. If you are scrubbed and wish to leave, you will have to find the appropriate time and ask the senior surgeon for permission.

- Mostimportant ofall, whateveryou do, do not bluff. Either guessing a patient's examination or answering a question about the anatomy, a bluff will destroy your reliability. Your attending, like your parents, knows when you are bluffing.

Although we may sound a little discouraging, we do not intend to scare people away from neurosurgery. In the end, let us remind you that every neurosurgeon was once a medical student and has a moral responsibility to make your time spent in the operating room worth it.

\section{REFERENCES}

I. Fox BD, Amhaz HH, Patel AJ, Fulkerson DH, Suki D, Jea A, Sawaya RE: Neurosurgical rotations or clerkships in US medical schools. J Neurosurg II4:27-33, 20 II.

2. Kozar RA, Lucci A, Miller CC, Azizzadeh A, Cocanour CS, Potts JR, Fischer CP, Brundage SI: Brief intervention by surgeons can influence students toward a career in surgery. J Surg Res III:I66-I69, 2003.

3. Liu CY, Spicer M, Apuzzo ML: The genesis of neurosurgery and the evolution of the neurosurgical oper- ative environment: part II-concepts for future development, 2003 and beyond. Neurosurgery 2003;52:20-33; discussion 3325, 2003.

4. Mueller PS, McConahey LL, Orvidas LJ, Lee MC, Bowen JM, Beckman TJ, Kasten MJ: Visiting medical student elective and clerkship programs: a survey of US and Puerto Rico allopathic medical schools. BMC Med Educ Io:4I, 2010.

5. Nathoo N, Cavusoglu MC, Vogelbaum MA, BarnettGH:In touch with robotics: neurosurgery for the future. Neurosurgery 56:42I-433; discussion 42I-433, 2005.
6. Stevens CD: Commentary: taking back Year 4: a call to action. Acad Med 85:1663-1664, 2010.

7. Walling A, Merando A: The fourth year of medical education: a literature review. Acad Med 85:1698I704, 2010.

Citation: World Neurosurg. (2012) 78, 1/2:18-19. DOl: 10.1016/j.wneu.2011.04.003 Journal homepage: www.WORLDNEUROSURGERY.org

Available online: www.sciencedirect.com

1878-8750/\$ - see front matter (C) 2012 Elsevier Inc All rights reserved. 